\title{
Fluorescein fundus photography of angioid streaks
}

\author{
BIJOYANANDA PATNAIK AND S. R. K. MALIK \\ From the Department of Ophthalmology, Maulana Azad Medical College and Associated Irwin and \\ G. B. Pant Hospitals, New Delhi, India
}

The most characteristic ocular lesions in pseudoxanthoma elasticum are the angioid streaks which may be seen in about 85 per cent. of cases. The associated features in the fundus are a peculiar mottled appearance (Shimizu, I96I), peau d'orange (Smith, Gass, and Justice, I964), and yellowish-white spots (salmon spots). While most subjects showing angioid streaks have pseudoxanthoma elasticum, clinically and histologically indistinguishable angioid streaks are also seen in Paget's disease (osteitis deformans) (Shaffer, Copelan, and Beerman, 1957), and sometimes in sickle cell disease (Paton, I959; Geeraets and Guerry, I960), familial hyperphosphataemia (McPhaul and Engel, r961), idiopathic thrombocytopenic purpura (Yatzkan, 1957), and lead poisoning.

The histopathological appearances of angioid streaks have been described by Hagedoorn (1939), Klien (1947), and Verhoeff (1948). Bruch's membrane takes up intense basophilic staining and shows evidence of deposition of metal salts such as calcium or iron. The membrane shows peripapillary cracks with radial extensions. Initially there is a thinning of the pigment epithelium. Later fibrovascular tissues from the choroid invade the retina. The underlying choroid capillaries undergo degeneration.

Many fluorescein fundus photographic studies have been made in cases of angioid streaks (Norton, Gass, Smith, Curtin, David, and Justice, 1965; Ernest and Krill, 1966; Tanenbaum and de Margerie, I966; Rosen, I968; Wessing and von Noorden, 1958). There is a broad agreement on the fluorescein pattern, but the interpretation of the fluorescence phenomenon is neither uniform nor satisfactory.

\section{Present investigations}

Three cases of angioid streaks have been studied by fluorescein angiography, and one of these, a case of pseudoxanthoma elasticum showing a complete picture of angioid streaks and associated features in the retina, is reported below.

\section{Case report}

A man aged 32 years with a histologically proven diagnosis of pseudoxanthoma elasticum was referred* for investigation of defective vision. The skin over the neck showed the characteristic changes of the condition (Fig. I, overleaf). The visual acuity was $6 / 24$ in the right eye and 6/12 in the left, not improved by glasses. Both fundi showed typical angioid streaks extending radially

Received for publication March 29, 1971

Address for reprints: Bijoyananda Patnaik, M.D., Department of Ophthalmology, Maulana Azad Medical College, New Delhi, India This work was supported in part by the Indian Council of Medical Research, New Delhi

*By a dermatologist, Dr. I). N. Mullay 


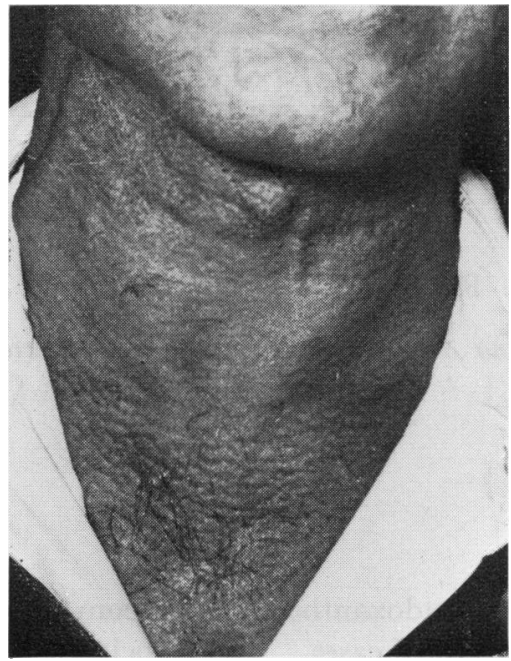

FIG. I Typical skin lesions on the ne:k

round the disc (Fig. 2A). The macula was traversed by the streaks on each side. The temporal periphery showed diffuse pigmentary mottling. In the left eye yellowish-white (salmon) spots were seen in bunches along the radiating streaks (Fig. 3A). There were also many isolated spots in both fundi. The electroretinogram was normal in both eyes.

Serial fluorescein fundus photography of the left eye was carried out by the technique of Novotny and Alvis (196I).

\section{Comments}

Fluorescence along the streaks was seen during the early arterial phase. Though the fluorescein pattern was sharply defined, it did not conform to the outline of the angioid streaks as seen with the ophthalmoscope (Fig. 2A, B, opposite). The early fluorescence was almost certainly a window phenomenon, i.e. the choroidal fluorescence was seen through the defects in the pigment epithelium which normally mask it.

Within seconds the fluorescent zone spread out with an ill-defined outline. The spreading fluorescein (Fig. 2D) obscured the nonfluorescent dark islets inside the fluorescent zone seen in the earlier phases (Fig. 2B, C). Rosen (1968) interpreted this phenomenon as a staining of the sclera. Tanenbaum and de Margerie (1966) considered it as an intravascular pooling of the dye rather than as an extravasation of dye in the choroid. How ever, any fluorescence on the choroidal side of the pigment epithelium should have the same outline as that of the window in the pigment epithelium, and this spread can only be seen if the dye spreads out on the retinal side of the pigment epithelium.

The evidence suggests that the unbound fluorescein passes readily through the choriocapillaris (Hill, Dollery, Hodge, and Scott, I964; Hill, I966; Wessing and von Noorden, 1958). It appears that this extravasated dye finds its way through the ruptured Bruch's membrane and the defects in the pigment epithelium and spreads out in front of this layer. In advanced cases with fibrovascular ingrowth from the choroid, the fluorescein on the retinal side of pigment epithelium could also originate from these new formed vessels. Persistence of fluorescence could be due to the retention of dye in the retina in proliferated tissue from the choroid, and in the sclera.

The fluorescein pattern in the region of the salmon spots (Fig. 3, overleaf) was of four types: 

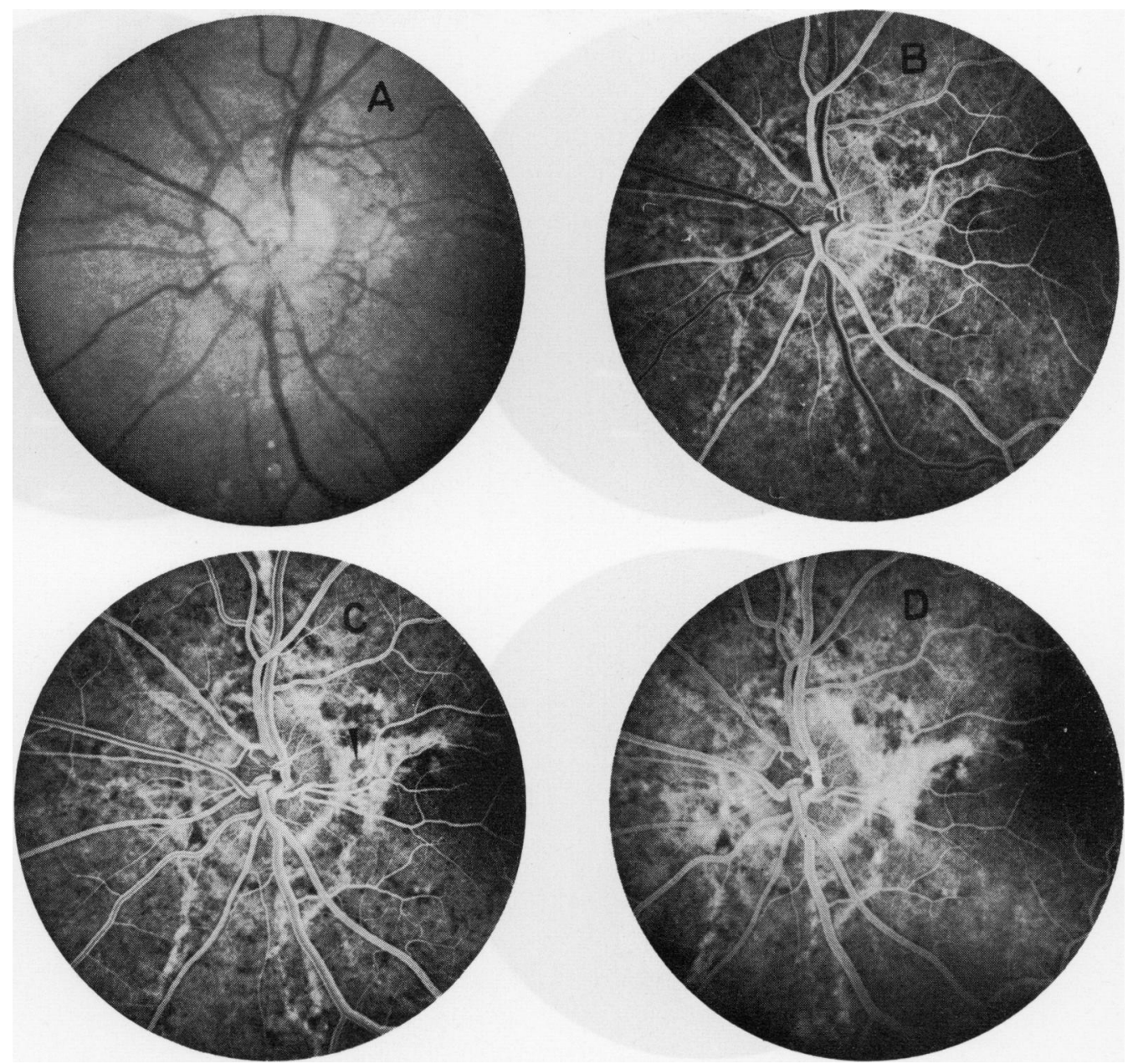

FIG. 2 (A) Left fundus, showing angioid streaks round the disc. A few of the many salmon spots are seen at the 6 o'clock position

(в) Fluorescein photograph at early venous phase. Fluorescence is seen along and not so much over the angioid streaks

(c) $2 \mathrm{sec}$. later there is increased density of fuoresecnce. The outlines of the fluorescent areas are fuzzy. Islets of poor fluorescence are surrounded by dense areas (arrow)

(D) 8 sec. later there is marked diffusion of the dye, specially round the disc. The nonfluorescent islets are swamped by leaking fuorescein

(i) A part of the area occupied by a bunch of salmon spots showed no fluorescence.

(ii) The area of fluorescence conformed to the size of the spots.

(iii) The fluorescence developed as a coherent background pattern independent of the salmon spots. They could not be identified in the fluorescein photographs.

(iv) The area of fluorescence was larger than that of the spots.

The position of the spots could be made out by a faint pigment ring corresponding to the outline of the spots. 


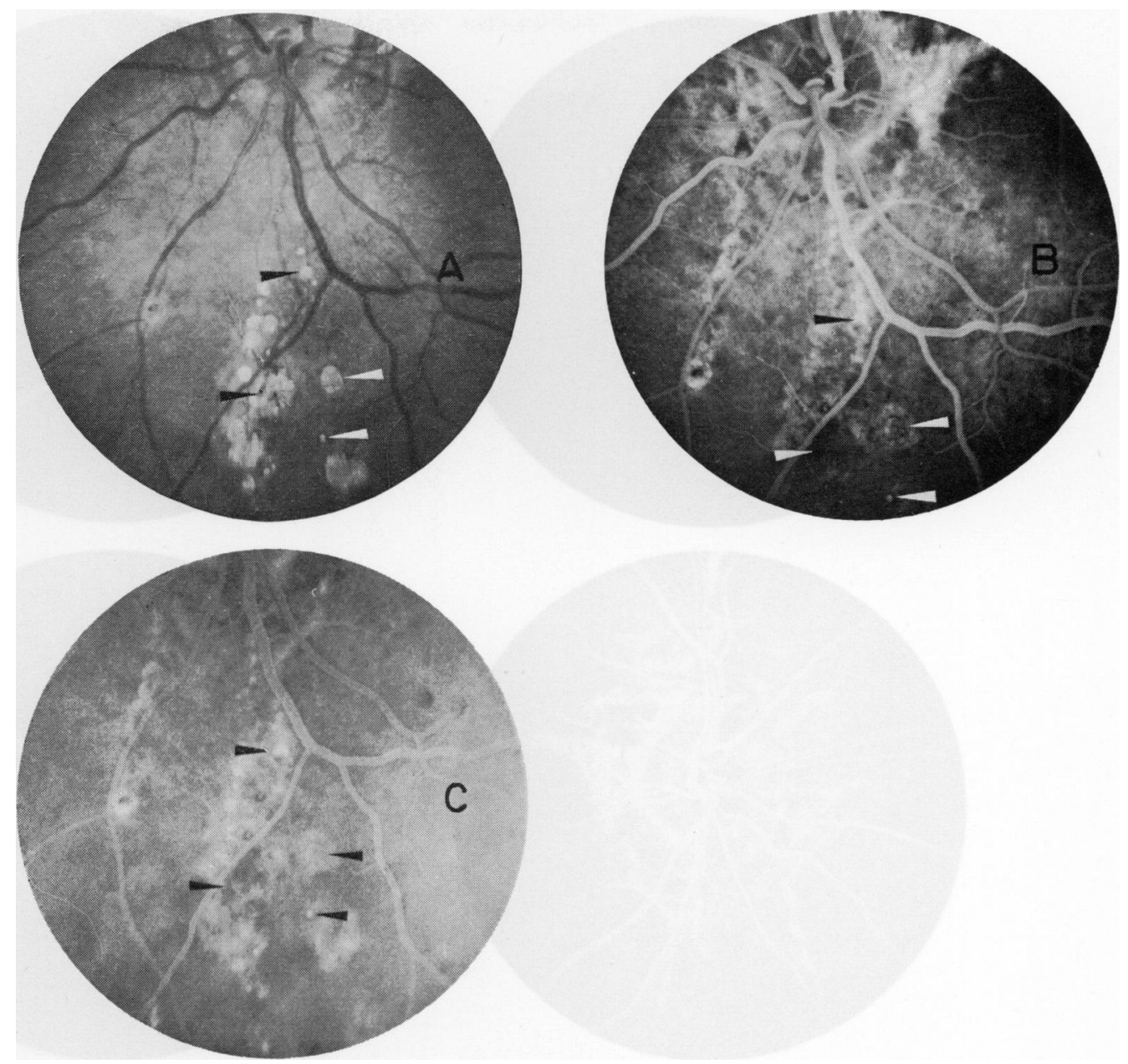

FIG. 3 (A) Left fundus, showing multiple salmon spots and streaks in discrete or confluent bunches

(B) Fluorescein photograph in arterio-venous phase on 2 nd injection about 3 min. after the first. Some of the salmon spots showed no fluorescence (arrow: bottom left). A small spot (arrow: bottom right) has assumed fluorescence of equal size. The fluorescence has developed as a coherent pattern in the background, where the identity of the salmon spots is lost (arrow: top left). Though the area of fluorescence is larger than the salmon spot, its outline can be made out (arrow top right)

(c) 5 min. after injection. Fluorescence of salmon spots as in (в). The reduced contrast is due to fluorescence in the anterior chamber

From these observations the following conclusions may be drawn. The spots were situated in areas showing widespread disturbances in the pigment epithelium and Bruch's membrane. The appearance of the spots in the fluorescein photographs seemed to depend on the change in the underlying pigment epithelium. If the pigment epithelium did not permit choroidal free fluorescein to reach the spots, they remained nonfluorescent (Type I). On the other hand, if there was a leakage, the spots took up the dye. When the area of leakage conformed to the size of the spots, they retained their outline as fluorescent 
spots (Type 2). However, if the leakage in the surrounding area was marked, the contrast was lost and the fluorescent spots lost their identity (Type 3). It appears that the spots are occasionally associated with a pigment pattern corresponding to the size of the spots; when the dye leakage was mild this pigment pattern could be made out (Type 4).

The possibility of pseudofluorescence or autofluorescence of the salmon spots may be excluded, because a group of these spots (Type I) remained nonfluorescent throughout the study, although their white refractile appearance was ophthalmoscopically identical with that of other salmon spots (Types 2 and 3 ) showing different degree of fluorescence (Fig. 3).

Histopathology suggests that these spots are hyaline deposits in the form of colloid bodies. Norton, Smith, Gurtin, and Justice (1964) believed that drusen did not take up fluorescein, but Rubinstein and Paton (1966) maintained that they did. Drusen of the disc has been found to be fluorescent on fluorescein angiography (Sanders and ffytche, 1967). Thus it would appear that, when exposed to extravasated free fluorescein, the hyaline bodies take up fluorescein and retain it for over 15 minutes.

\section{Summary}

A case of pseudoxanthoma elasticum with angioid streaks was examined by fluorescein fundus photography. The pattern of fluorescence around the salmon spots is described. An attempt has been made to interpret the behaviour of fluorescein in the presence of angioid streaks.

\section{References}

ERNEST, J. T., and Krill, A. E. (I966) Amer. J. Ophthal., 62, I

GEEREATS, W. J., and GUERRY, D. (I960) Ibid., 50, 2 I 3

HAGEDOORN, A. (1939) Arch. Ophthal., 21, 746

HILL, D. W. (I g66) Trans. ophthal. Soc. U.K., 86, I 25

-, DOllery, c. T., hodge, J. V., and scott, D. J. (1964) Proc. roy. Soc. Med., 57, 500

KLIEN, B. A. (I947) Amer. 7. Ophthal., 30, 955

McPhaul, J. J., and engel, F. L. (I96I) Amer. 7. Med., 31, 488

NORTON, E. W. D., GASS, J. D. M., SMITH, J. L., CURTIN, v. T., DAVID, N. J., and JUSTIGe, J. (1965) Trans.

Amer. Acad. Ophthal. Otolaryng., 69, 631 -, SMith, J. W., CURTIN, v. T., and Justice, J. (1964) Ibid., 68, 755

NOVOTNY, H. R., and ALvis, D. L. (I96I) Circulation (N.Y.), 24,82

PATON, D. (1959) Arch. Ophthal. (Chicago), 62, 852

ROSEn, E. (I968) Amer. J. Ophthal., 66, 236

RUbinstein, K., and Paton, A. (1966) Trans. ophthal. Soc. U.K., 86, 139

SANDERS, M. D., and FFYTCHE, T. J. (1967) Ibid., 87, 457

Shaffer, B., Copelan, h. w., and beerman, h. (1957) A.M.A. Arch. Derm., 76, 622

shimizu, к. (196r) Jap. F. Ophthal., 5 (1), 12

SMITH, J. L., GASS, J. D. M., and JUSTICE, T. (I964) Brit. J. Ophthal., 48, 517

TANENBAum, H. L., and MARgerie, J. DE (ig66) Canad. F. Ophthal., I, 22 I

yATZKAN, D. N. (1957) Amer. J. Ophthal., 43, 219

VERHOEFF, F. H. (1948) Brit. J. Ophthal., 32, 53 I

Wessing, A., and NoORden, G. K. von (1958) "Fluorescein Angiography of the Retina". Mosby,

St. Louis 